\title{
Physical Asset Management Practices in Industry: Comparisons between Greece and Other EU Countries
}

\author{
Christos Emmanouilidis ${ }^{1}$ and Kari Komonen ${ }^{2}$ \\ ${ }^{1}$ ATHENA Research \& Innovation Centre, ATHENA RIC Building \\ Kimeria University Campus, 67100, Xanthi \\ Greece chrisem@ceti.athena-innovation.gr \\ ${ }^{2}$ Promaint, Finland \\ Kari.Komonenesaunalahti.fi
}

\begin{abstract}
Physical asset Management is "the optimal life cycle management of physical assets to sustainably achieve the stated business objectives". A "physical asset" is defined as a physical item that has potential or actual value to an organization. During 2011-2012 the European Federation of National Maintenance Societies (EFNMS) European Asset Management Committee (EAMC) carried out a survey of industries seeking to map physical asset management practices. The survey contained questions concerning the business environment of respondents, management practices, key performance indicators usage, organizational policies and driving factors. This paper presents the survey deeper findings regarding the responses, influences of industrial sector and business environment on physical asset management practices, identification of typical existing asset management profiles and improvement suggestions. Focus is given on comparing asset management practices between Greece and other EU countries, offering insight into different technological, business environment and other factors influencing physical asset management practices.
\end{abstract}

Keywords: Asset Lifecycle Management, Maintenance in Manufacturing.

\section{Introduction}

Physical asset Management is "the optimal life cycle management of physical assets to sustainably achieve the stated business objectives". The concept takes into account capacity considerations, design, investments, operations, maintenance of production equipment and disposals. One of the main tasks of Asset Management is to guarantee that the changing business requirements and physical assets match together in an optimal way, taking into account all life cycle aspects of equipment. In the present business environment, Physical Asset Management is becoming a key challenge for business organisations and has acquired more importance as a management function than ever before. However, the state of implementing Physical Asset Management best practices in industry is not sufficiently well recorded or documented.

The current financial climate makes it all the more important to look into such practices and trends within European Industry [1]. Among the tools that can be used 
to assess the maturity level of the Asset Management function is the PAS 55 model, developed by the Institute of Asset Management in the UK [2]. Other initiatives have sought to map specific aspects of Maintenance Management practice in some countries, such as Italy [3] and Spain [4]. A European-wide survey or a more global one over a common baseline was missing.

An initiative to support establishing the current status of Physical Asset Management was taken by the European Federation of National Maintenance Societies (EFNMS) European Asset Management Committee (EAMC), with the launch in 2011 of a survey in order to map Physical Asset Management practices in EU industries [5][6]. An initial analysis of the obtained results has shed light into the current state of Asset Management practice in the EU and more work on supplementing the currently obtained results is foreseen [7]. With Greece being among the countries severely hit by the financial crisis and with its industry just starting to switch to more export-oriented operation [8], it is of particular interest to focus on the survey results to draw some insight into differences between physical asset management practices in Greece compared to the rest of Europe. This paper presents an analysis of the main findings of such a comparison. An extension of the survey is planned for 2013-2014.

\section{Physical Asset Management}

Physical Asset Management integrates functions from different ISA-95 layers, including operational, tactical and strategic functions and therefore requires an integrated approach in decision making. It integrates asset creation and development, asset operation, upkeep of assets, repair and upgrading of assets, as well as recycling and disposals. An important part of asset development is the determination of capacity needs and capacity creation which involves investment planning and investment execution. Asset operation is the handling of assets for their intended function, mostly production, and especially the part of production operations that influences assets and their prevailing production capability. The third dimension, upkeep, stands for the maintenance function. Asset management strongly supports sustainable development by striving at efficient use of scarce resources taking into account market, technological, legal and normative constraints, market dynamics, as well as sustainability. Upgrades go beyond replacements, in the form of repair, renovation or remanufacturing. An important aspect of physical asset management is to strike the right balance between performance, cost and risk in pursuing the enterprise goals. It supports managing investments, capacity and production in a more efficient, better quality-assured, safer and more competitive way. There is a need for more efficient asset management to deal with the different sources of losses during the life cycle of production equipment and physical assets, thus demanding more efficient asset management, such as:

- economic lifetime is not in balance with technical lifetime

- all processes are not functioning at the same operating rate

- during process and product transitions production capacity of large concentration of assets is utilised

- demand does not match with capacity 
- during installation and start of investment production losses may be huge

- Overall Equipment Effectiveness (OEE, including low availability, low speed and low quality rate) causes production losses

- due to low flexibility of assets equipment is used in ineffective way (product mix and insufficient adaptation to demand fluctuations)

- design and manufacturing of equipment is not up to date.

To drive improvements in Physical Asset Management practice, the current status needs to be identified and this has been the primary aim of the EAMC survey.

\section{Physical Asset Management Survey}

To carry out this exploratory survey EAMC launched a survey of European Industry, on the basis of a questionnaire designed to collect background information for the development activities in the area of Physical Asset Management and the maintenance function as a part of Physical Asset Management [6]. Another objective was to offer European organisations insight into the mode of operations in Physical Asset Management within various business and technology environments. The survey questionnaire included the following groups of questions:

A. Organisation and management principles

1. Organisations business environment (7 questions): e.g. rate of change, life cycle phase of the industry and principal business drivers

2. Organisation and decision making in the area of asset management (5 questions): e.g. financial responsibility of asset management, participation in various phases of investment processes

3. Management and control (7questions): e.g. use of aggregate and other key performance indicators for asset management, criteria for investment decisions

4. Asset knowledge management (4 questions): e.g. coverage of criticality analyses, use of asset history systems, working culture

B. Maturity of management activities

1. Policy and strategy (4 questions): e.g. development of asset management policy and strategy, demand analysis, asset management plans

2. Whole Life Costing (WLC) justification and risk analysis (3 questions): e.g. evaluation of capital expenditure requirements for the whole lifecycle

3. Asset lifecycle management (6 questions): e.g. various lifecycle phases practices

4. Asset knowledge management (4 questions): e.g. definition of standards, guidelines or best practices for classifying, collecting and storing asset knowledge

5. Asset management capability (3 questions) e.g. auditing and review the safety, efficiency and effectiveness of asset management activities

6. Asset management review and improvement (3 questions): e.g. measurement, development and monitoring the organisation's asset management performance

C. Future driving forces of asset management activities

Long term return on assets, OEE and legislation are among 10 proposed drivers. 
The questionnaire is available at: https://e-lomake.fi/lomakkeet/2033/lomake.html. The survey was implemented during spring 2011 and organisations representing 24 countries and 23 industrial sectors contributed the study.

\section{$4 \quad$ Greek Industry Survey Findings}

The analysis aims at indentifying the current status regarding Greek industry, compared to the rest of Europe. This is of interest especially since the current crisis puts on severe pressure for improvements in competitiveness, which currently, according to the latest figures from the World Economic Forum shows Greece to be a stubbornly persistently low performer [9]. This is despite Greece featuring at a relatively high ranking in terms supporting pillars, such as infrastructure, technological readiness and educational support. Due to the specifically negative macroeconomic environment, Greek industry would have to perform even better in terms of Physical Asset Management practices to raise its competiveness level.

The EAMC Asset Management survey has drawn participation from 33 Greek industries. These were distributed among the following sectors:

- Manufacture of food products

- Manufacture of wood and of products of wood and cork, of furniture, etc

- Manufacture of paper and paper products

- Manufacture of coke \& refined petroleum, chemicals \& chemical products

- Manufacture of basic pharmaceutical products and pharmaceutical preparations

- Manufacture of rubber and plastic products

- Manufacture of fabricated metal products, of machinery and equipment, of motor vehicles, etc.

- Other manufacturing

- Distribution of gaseous fuels through mains

- Water transport / Other utilities

- Service provider / facilities management

Comparative results were obtained against 102 responses from other European countries. In general, some variations were found between Greek and other European industries in terms of organisational and management issues, as well as in terms of future drivers. No major variations were observed in the maturity of asset management activities. This may be an indication that physical asset management is not falling behind other European countries management, but other organisational and even legislative issues are considered as needing more improvement. When considering only manufacturing industries, more deviations are found. A first difference is observed in the lifecycle phase of industry wherein Greek distribution was more skewed towards slow-growth and mature to aging industry (Fig. 1). Another difference is on the planned operating rate of the production equipment. In Greece, the obtained responses indicate that this peaks at the middle-usage rage between 51-75\%, whereas overall in responses obtained from all European countries, the responses indicate a 


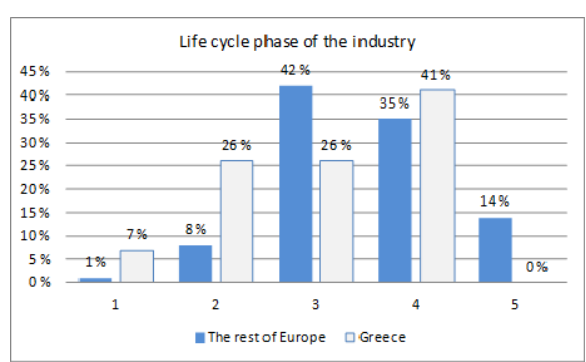

Fig. 1. Lifecycle phase of industry. 1. Emerging 2. Fast growth. 3. Slow growth 4. Mature. 5. Aging / Declining

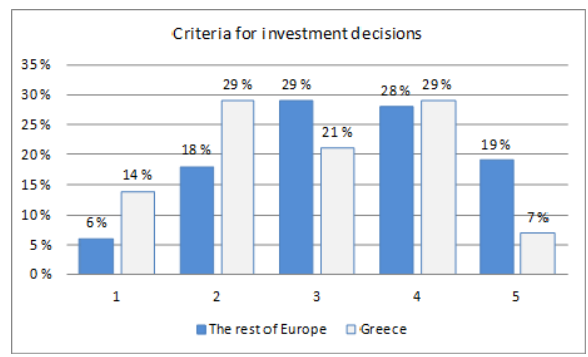

Fig. 3. Criteria for investment decisions: 1 : Cost of purchase, 2: Cost of purchase and installation, 3: All the costs of investment before full scale production, 4: Life-cycle costs, 5: Life-cycle profit

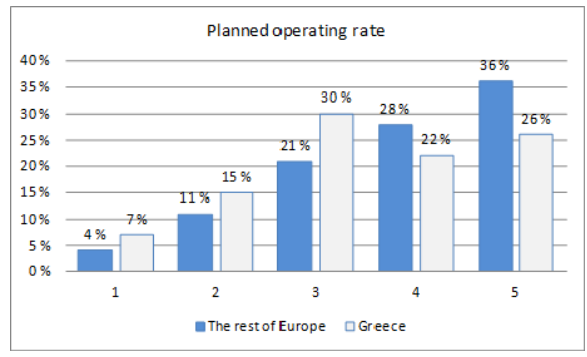

Fig. 2. Planned operation rate: 1: $<25 \%, 2$ : 25-50\%, 3: 51-75\%, 4: 76-90\%, 5: >90\%

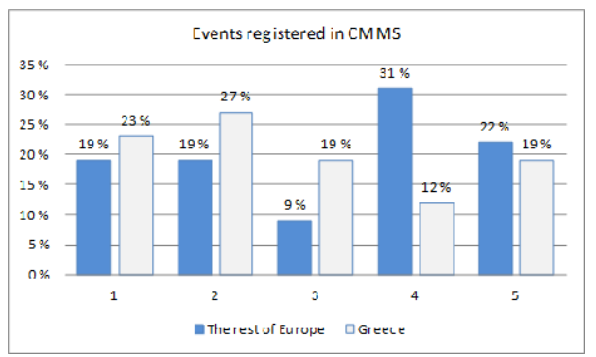

Fig. 4. Asset events recorded in CMMS: 1: $<10 \%, 2: 10-40 \%, 3: 41-70 \%, 4: 71-95 \%, 5$ : $>95 \%$

much more skewed distribution towards higher operating rates (Fig. 2). One of the few deviations in the asset management practices was in the criteria for investment decisions. In Greece a clear majority of the respondents used investment costs-based decision making, whereas the other regions utilized more life cycle cost or profit based decision making (Fig. 3). A reason behind this tendency can probably be the deviating life cycle phase structure of the industry in Greece.

In Greece, financial responsibility for physical asset management seems to be more on the shoulders of the maintenance function, whereas in the group of the other regions it is allocated to the asset manager, asset management teams or the top management. The extent of usage of asset management information systems, such as that of a computerised maintenance management system (CMMS) also appears to differ. Overall, a higher proportion of asset events tend to be registered in a CMMS in other countries, compared to Greece (Fig. 4).

The identification of risk-based maintenance requirements does not show a strong concentration either into low or high-priorities in industries (Fig. 5). Generally, most industries consider it to be in place, but there is a higher proportion of European industries that consider it effective and fully integrated with all other relevant aspects 


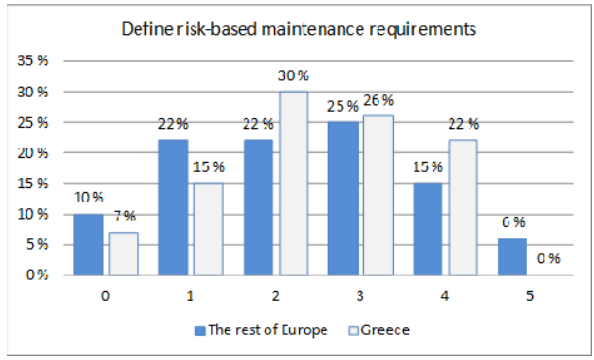

Fig. 5. Risk-based maintenance requirements: 0 : least -5 : maximum

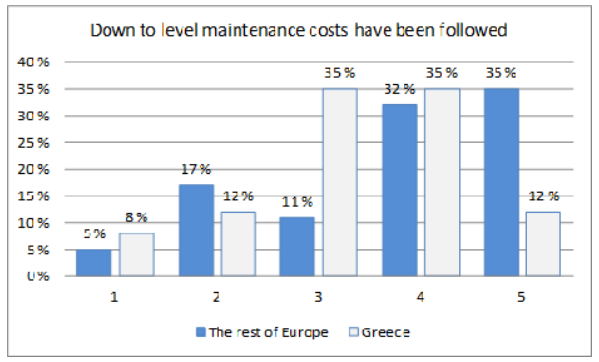

Fig. 6. The level, down to maintenance costs have been followed

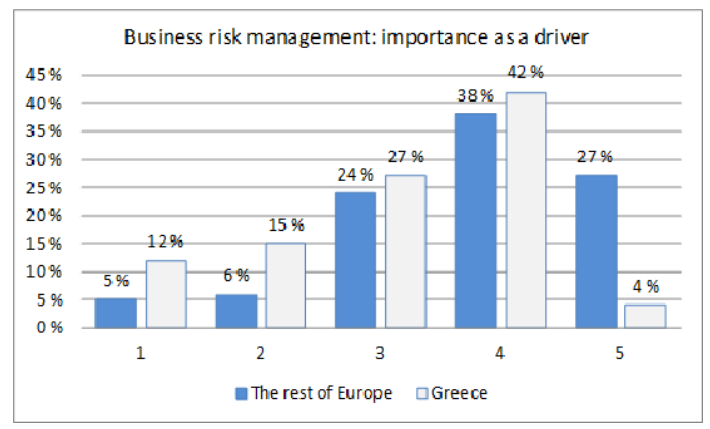

Fig. 7. 'Business risk management' importance: 1: least -5 : maximum

of asset management in all other parts of the organisation, whereas in Greece the same proportion considers it effective but more see it integrated. The best practice is missing in the responses from Greece.

More deviations can be found if we focus on manufacturing industries. Other regions in Europe apply the follow-up of maintenance costs at the more detailed indenture level, compared to Greece (Fig. 6). Deviations are also found in producing annual asset management plans, acquisition of assets and ensuring new assets meet specified requirements. Respondents in Greece were not as satisfied with procedures as in the other regions.

Considering the drivers of asset management decisions and practices, business risk management is in general considered significant or very significant, with a smaller proportion in Greek industry considering it very significant compared to other countries. On the question whether these variations depend on real differences in asset management practices or whether they are due to variations in the business technological environment, multivariate regression analysis shows that. 'Expected economic age of production equipment' and 'business risk management as a driver' have the strongest influence on investment criteria (Fig. 7). Greek asset management practices have some impact on this factor, but statistical significance was only indicative, with explanatory power at $0.27 \%$. 
Table 1. Factors having impact on investment decision criteria

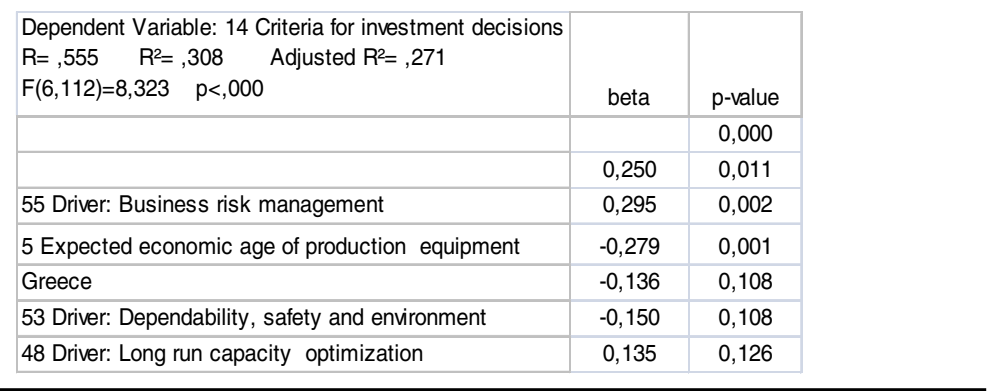

Table 2. Factors having impact on financial responsibility for AM of existing equipment

\begin{tabular}{|l|c|c|}
\hline $\begin{array}{l}\text { Dependent Variable: 8 Financial responsibility for AM of } \\
\text { existing equipment } \\
\mathrm{R}=, 460 \quad \mathrm{R}^{2}=, 211 \quad \text { Adjusted } \mathrm{R}^{2}=, 184\end{array}$ & $\mathrm{p}$-value \\
\begin{tabular}{l}
$\mathrm{F}(4,115)=7,7021 \mathrm{p}<, 000$ \\
\hline Intercept
\end{tabular} & & \\
\hline 55 Driver: Business risk management & 0,323 & 0,176 \\
\hline Greece & $-0,282$ & 0,000 \\
\hline 3 Life cycle phase of main products & 0,183 & 0,030 \\
\hline Others & $-0,203$ & 0,032 \\
\hline
\end{tabular}

Business risk management as a driver, life cycle phase of main products and Greek specific practices seem to have some influence on financial responsibility for asset management activities (Tables 1-2). The overall explanatory power of the statistical model was $0.18 \%$. In the case of 'Maintenance costs calculation Greek specific practices seem to have some impact on the results, but the impact was not very strong. The same applies to 'Events registered in CMMS'.

\section{Conclusion}

Asset management within manufacturing is considered an increasingly important contributor towards enhancing production quality, safety, performance and efficiency, as well as environmental sustainability Nonetheless, the status of implementation of Physical Asset Management best practices in industry is not sufficiently recorded or documented. The EFNMS via its EAMC Committee has taken the initiative to seek to map the status of Physical Asset Management in Europe. This action is taken by the EFNMS Asset Management Committee (EAMC), with the launch in spring 2011 of an EU-wide survey in order to map Physical Asset Management practices in the different kind of business environments in Europe. The survey has identified key areas for improvement among European industry, such as 'Risk \& Review', 'Asset Knowledge' and 'Asset Management Strategy and Planning'. Focusing specifically on Greek 
industry, there is a need to place greater emphasis on the importance of specific drivers for asset management. Greater information integration and enabling technologies usage should be sought, while asset management linkage with production and asset utilisation performance aspects, such as production equipment planned rate should be better established. Other aspects such as risk-based prioritisation, lifecycle considerations and return on assets are worth improved attention. A greater push within Greek industry is needed to better establish links between asset management and upper management functions. Decision making should not be solely driven by acquisition and installation costs considerations, but life cycle costs and profits should be taken more into account. Asset management in Greek industry is advised to manage costs not only at a macro-level but at a lower asset level, and indenture could also reflect on this. The nature of the reported survey has been exploratory but is a good basis for developing future studies, providing benchmarking findings against which to seek to place current practices in the infrastructure sector and manufacturing industries.

Acknowledgements. The EFNMS Physical Asset Management Survey was designed by the EAMC Committee of EFNMS and supported by National Maintenance Societies and especially the Hellenic Maintenance Society (HMS) on Greek Industry. The authors wish to acknowledge the contribution of EAMC members on the survey results. The first author wishes to acknowledge partial support through GSRT (grant 09SYN-71-856, project WelCOM) and the support of P. Pistofidis for the survey of Greek Industry.

\section{References}

1. van der Lei, T., Herder, P., Wijnia, Y. (eds.): Asset Management: the state of the art in Europe from a life cycle perspective. Springer (2012)

2. IAM: IAM PAS55:2008. London: Institute of Asset Management (2008)

3. Fumagalli, L., Macchi, M., Rapaccini, M.: Computerized Maintenance Management Systems in SMEs: A Survey in Italy and Some Remarks for the Implementation of Condition Based Maintenance. In: 13th IFAC Symposium on Information Control Problems in Manufacturing, INCOM 2009, Moscow, Russia, pp. 1615-1619 (2009)

4. Carnero, M.-C.: Condition-based maintenance in small industries. In: AMEST 2012, 2nd IFAC workshop on Advanced Maintenance Engineering Services and Technology, Seville, Spain (IFAC), November 22-23 (2012)

5. EFNMS-EAMC: How organizations manage their physical assets in practice, EFNMS Asset Management Survey (EFNMS) (2012)

6. Komonen, K.: EFNMS Asset Management Survey 2011: How organizations manage their assets in practice. Maintworld Magazine 3(3) (2011)

7. Komonen, K.: European Asset Management Practices: the results of EFNMS asset management survey, Euromaintenance 2012, Belgrade, Serbia (2012)

8. FEIR:, The Greek Economy: 3/2012, Foundation for Economic and Industrial Research (FEIR) (2011)

9. Schwab, K. (ed.): The Global Competitiveness Report: 2012-2013. World Economic Forum (2012) 